\title{
ANALISIS NERACA AIR DAS MUARI DI DISTRIK ORANSBARI KABUPATEN MANOKWARI SELATAN
}

\author{
Puji L.Mansnembra ${ }^{1}$, Rosalina R. Mirino ${ }^{2 *}$, Khristian Enggar Pamuji ${ }^{3}$, \\ ${ }^{1,2,3}$ Prodi Fisika Jurusan Fisika FMIPA UNIPA \\ Jl. Gunung salju Amban, Manokwari - Kode Pos: 98314 \\ email korespondensi: rosmirino@gmail.com
}

\begin{abstract}
ABSTRAK
Penelitian tentang Analisis Neraca Air DAS Muari bertujuan mengetahui ketersediaan air di DAS Muari, kebutuhan air domestik dan non domestik serta neraca DAS Muari. Data yang digunakan dalam penelitian ini yaitu data primer dan data sekunder. Data primer berupa pengukuran pada penampang kering sungai untuk mengetahui kapasitas tampung sungai serta karakteristik DAS Muari, sedangkan data sekunder berupa data iklim (curah hujan bulanan, hari hujan, temperatur dan lama penyinaran selama 10 tahun terakhir dari tahun 2009-2018 yang diperoleh dari BMKG Manokwari Selatan), data kebutuhan domestik dan data kebutuhan non domestik. Data yang telah diperoleh kemudian diolah menggunakan MS. Excel dan Arcgis. Hasil dari pengolahan data untuk ketersediaan air DAS mantap diperoleh nilai sebesar 5.400.697,68 $\mathrm{m}^{3} /$ tahun, untuk kebutuhan air domestik dan non domestik sebesar 4.578.872,45 $\mathrm{m}^{3} /$ tahun. Dari nilai ketersediaan air dan kebutuhan air maka diperolehlah neraca air DAS Muari sebesar $821.825,23 \mathrm{~m}^{3} /$ tahun, nilai ini menunjukkan bahwa DAS Muari mengalami surplus.
\end{abstract}

Kata Kunci : Neraca Air, DAS Muari, Ketersediaan Air, Kapasitas Tampung Sungai

\section{PENDAHULUAN}

Air merupakan sumber daya alam yang sangat dibutuhkan oleh semua makhluk hidup khususnya manusia. Definisi sumberdaya air dalam UU Sumberdaya Air (UU No. 7 Tahun 2004) menyebutkan bahwa sumber air adalah tempat atau wadah air alami dan atau buatan, yang terdapat pada, di atas, ataupun di bawah permukaan, air tanah, air hujan, dan air laut yang berada di laut.

Ketersediaan sumber daya air merupakan salah satu modal yang diperlukan untuk menunjang swasembada pangan dan pemenuhan kebutuhan domestik. Pemenuhan kebutuhan tersebut diperlukan pemanfaatan sumber daya air dengan memperhatikan ketersediaan air permukaan pada Daerah Aliran Sungai (DAS) sebagai sumber daya yang diprioritaskan pengambilannya (Bayuaji, 2015).

Kebutuhan air akan terus meningkat seiring dengan bertambahnya pertumbuhan jumlah penduduk dan industri. Ketersediaan air pada saat ini masih memenuhi kebutuhan, namun pada masa mendatang peluang untuk terjadinya krisis air akan terus meningkat. Pengelolaan DAS yang kurang tepat akan menyebabkan terjadinya ketidakseimbangan antara ketersediaan air pada DAS yang akan terus menurun dengan kebutuhan air yang terus meningkat. Perhitungan neraca air sangat diperlukan untuk memberikan gambaran mengenai ketersediaan air. Neraca air merupakan hubungan antara aliran air ke dalam tanah yang berupa masukan (input) 
dengan keluaran (output) dalam rentang waktu tertentu.

Distrik Oransbari merupakan salah satu Distrik yang sedang berkembang di Kabupaten Manokwari Selatan. Jumlah penduduk yang semakin bertambah, luas lahan pertanian yang kian meningkat dan sarana prasarana yang terus dibangun akan meningkatkan kebutuhan air. Pengembangan dan pembangunan di Distrik Oransbari diusahakan tidak melebihi dari daya dukung lingkungan.

Sungai Muari berada di Distrik Oransbari Kabupaten Manokwari Selatan, merupakan salah satu sumber air yang dimanfaatkan oleh masyarakat sekitar. Pemanfaatan sungai tersebut untuk keperluan sehari-hari atau domestik, keperluan pada lahan pertanian, dan dipergunakan sebagai tempat rekreasi. Seiring berjalannya waktu, perlu dilakukan penelitian pada sungai Muari terkait ketersediaan air sehingga air sungai ini dapat dimanfaatkan secara kontinyu. Adapun tujuan dilakukannya penelitian ini yaitu untuk mengetahui ketersediaan air di DAS Muari, kebutuhan air domestik dan non domestik serta neraca DAS Muari.

\section{METODE PENELITIAN}

Penelitian dilaksanakan kurang lebih 6 bulan yang dimulai dari bulan Agustus 2019 - Februari 2020 dan penelitian ini dilakukan pada DAS Muari di Distrik Oransbari Kabupaten Manokwari Selatan. Peta Lokasi penelitian dapat ditunjukkan pada Gambar 1 ..

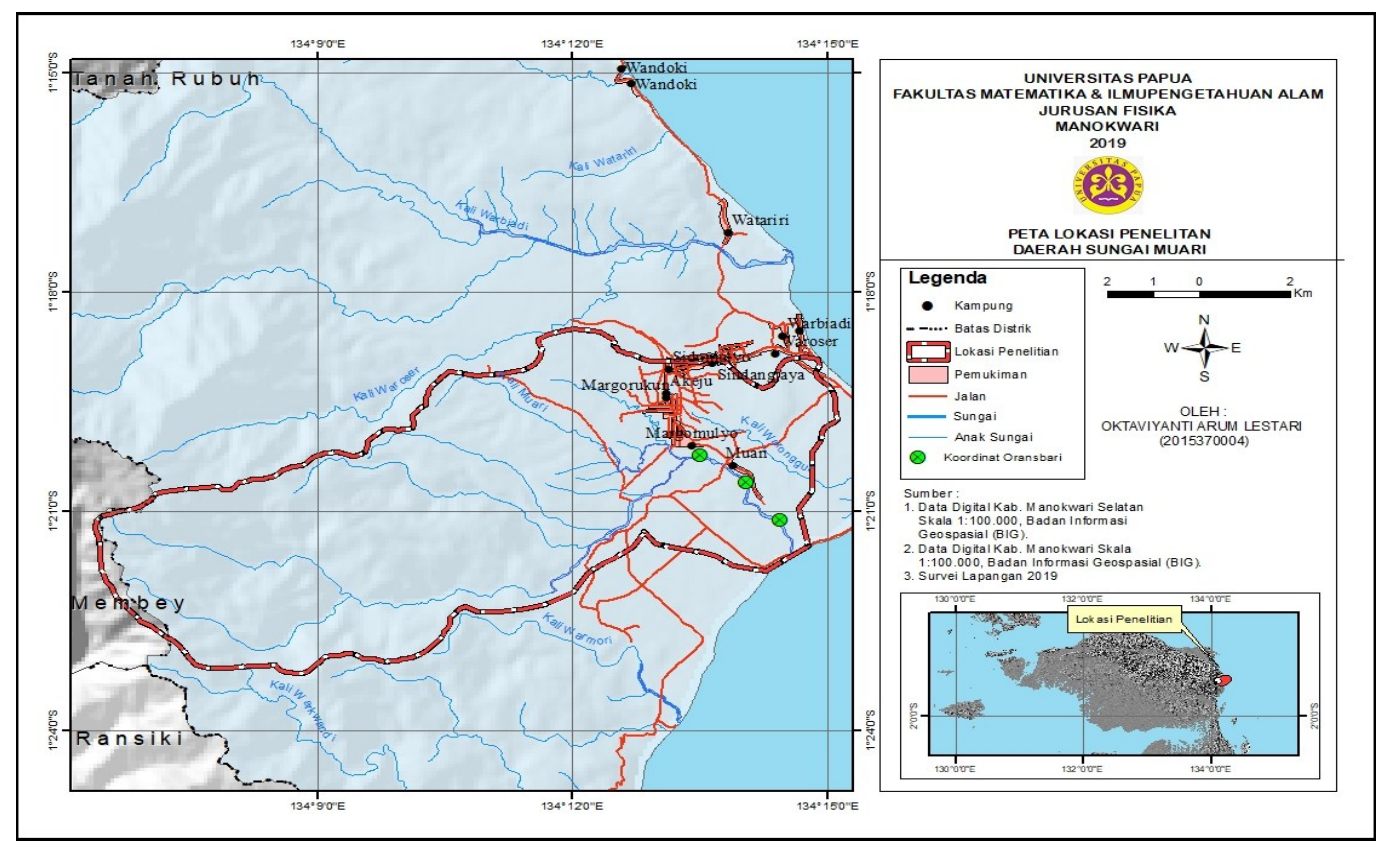

Gambar 1. Peta Lokasi Penelitian

Penelitian ini dimulai dari studi literatur, pengumpulan data dan analisis data. Studi literatur merupakan tahapan awal untuk melakukan serta mencari literatur mengenai penelitian. Pengumpulan data berupa data primer dan data sekunder. Data primer diperoleh dari pengukuran langsung di lapangan berupa pengukuran luas penampang kering untuk memperoleh kapasitas tampung sungai. 
Data sekunder berupa data iklim yaitu data curah hujan, hari hujan, temperatur, lama penyinaran selama 10 tahun terakhir (2009-2018) yang diperoleh dari BMKG Manokwari Selatan untuk memperoleh ketersediaan air. Data sekunder lainnya yaitu data berupa kebutuhan air domestik dan non domestik. Analisis data meliputi analisis iklim menggunakan metode SchmidFerguson dan Mohr, analisis evapotranspirasi, analisis DAS, analisis ketersediaan air menggunakan metode Thrownwaite, analisis kebutuhan air domestik dan non domestik yang beracuan pada SNI (Standar Nasional Indonesia 19678.1-2002 tentang Penyusunan Neraca Air Sumber Daya Spasial) dan analisis neraca air dengan membandingkan ketersediaan air dan kebutuhan air.

\section{$>$ Pengolahan Data}

1) Luas DAS Muari diperoleh dengan menggunakan arcgis, sehingga dapat menentukan bentuk DAS Muari.

2) Kapasitas tampung sungai diperoleh dengan mengukur penampang kering (A) sungai yang dibagi kedalam segmen-segmen serta nilainya dapat dihitung menggunakan metode mean section pada persamaan :

$$
a_{n}=\left(\frac{\mathrm{d}_{n}+\mathrm{d}_{n+1}}{2}\right) x \mathrm{~b}_{n+1}
$$

dimana :

$\mathrm{d}_{n}$ : Kedalaman sungai ke $\mathrm{n}$

$\mathrm{d}_{n+1}$ : Kedalaman sungai ke $\mathrm{n}+1$

$\mathrm{b}_{n+1}$ : Kedalaman seksi ke $\mathrm{n}$ kemudian dikalikan dengan kecepatan aliran (v) yang diperoleh dari rumus manning pada persamaan :

$$
\mathrm{v}=\frac{1}{n} \mathrm{x} \mathrm{R}^{2 / 3} \times \mathrm{S}^{1 / 2}
$$

dimana :

$\mathrm{v}:$ Kecepatan rata-rata $(\mathrm{m} / \mathrm{s})$

$\mathrm{R}$ : Radius hidrologik (m)

S : Gradien hidrolik

$\mathrm{n}$ : Koefisien kekasaran manning

3) Untuk nilai Qp (run off) dihitung menggunakan persamaan :

$$
\mathrm{Q}=\text { C.I.A }
$$

dimana:

$\mathrm{Q}$ : Debit aliran $\left(\mathrm{m}^{3} /\right.$ hari $)$

$\mathrm{C}$ : Koefisien run off

I : Intensitas hujan maksimum ( $\mathrm{mm} /$ hari)

A: Luas daerah aliran sungai $\left(\mathrm{m}^{2}\right)$

dimana nilai $\mathrm{C}$ (koefisien) ditentukan berdasarkan peta tutupan lahan dan kelerengan. Data yang digunakan untuk menghitung intensitas maksimum yaitu data curah hujan bulanan dan data hari hujan selama 10 tahun terakhir (2009-2018) yang diperoleh Badan Meteorologi dan Geofisika Stasiun meteorologi Manokwari Selatan selama 10 Tahun (2009-2018) di wilayah Kabupaten Manokwari Selatan.

4) Data iklim berupa data temperatur (T) dalam satuan ${ }^{\circ} \mathrm{C}$ diperoleh dari Badan Meteorologi dan Geofisika Stasiun meteorologi Manokwari Selatan selama 10 Tahun (2009-2018) di 
5) wilayah Kabupaten Manokwari Selatan. Data temperatur rata-rata bulanan ini digunakan untuk menghitung nilai evapotranspirasi potensial bulanan belum terkoreksi (EPx) berdasarkan persamaan :

$$
\mathrm{EPx}=1,6(10 . t / \mathrm{I})^{\mathrm{a}}
$$

dimana :

EPx : Evapotranspirasi potensial bulanan belum terkoreksi ( $\mathrm{cm} / \mathrm{bulan}$ )

t : suhu rata-rata bulanan $\left({ }^{\circ} \mathrm{C}\right)$

I : Akumulasi indeks panas dalam setahun

a : Koefisien yang tergantung dari tempat

Nilai koefisien bergantung tempat (a) diperoleh dari persamaan :

$$
\begin{gathered}
a=0,000000675 \times I^{3}-0,0000771 \times I^{2}+ \\
0,01792 \times I+0,49239
\end{gathered}
$$

Untuk memperoleh nilai (I) indeks panas dalam setahun dapat dihitung menggunakan persamaan :

$$
\mathrm{I}=\sum_{i=1}^{12} i
$$

Untuk mendapatkan nilai (i) indeks panas bulan dapat dihitung dengan persamaan :

$$
i=(\mathrm{t} / 5)^{1,514}
$$

Nilai-nilai yang telah diperoleh di atas selanjutnya dapat digunakan untuk menghitung nilai PET (Evapotranspirasi potensial terkoreksi) pada persamaan :

$$
\mathrm{PET}=\mathrm{C}(10 . \mathrm{t} / \mathrm{I})^{1,514} \times(\mathrm{d} / 12) \times(\mathrm{N} / 30)
$$

dimana :

C : : 1,6 d : Jumlah rata-rata lama penyinaran

$\mathrm{N}$ : Jumlah hari dalam sebulan

6) Setelah memperoleh semua nilai tersebut, dapat dihitung ketersediaan air DAS yang mantap menggunakan persamaan :

$$
\mathrm{Pa}=((\mathrm{P}-\mathrm{PET}) \times \mathrm{A}) \times 30 \%
$$

7) Data sekunder lainnya yaitu data jumlah penduduk yang sudah diperbaharui untuk tahun 2019 di wilayah Kabupaten Manokwari Selatan yang diperoleh dari masingmasing Kepala Kampung. Perhitungan kebutuhan air domestik dan non domestik yang mengacu pada SNI (Standar Nasional Indonesia 19-678.12002)

\section{Analisis Data}

Data primer pengukuran langsung di lapangan berupa pengukuran luas penampang kering digunakan untuk memperoleh kapasitas tampung DAS. Setelah memperoleh luas DAS, bentuk DAS, kapasitas tampung DAS dan run off digunakan untuk menganalisis karakteristik DAS Muari. Data sekunder (data iklim) digunakan untuk menganalisis klasifikasi iklim menurut Schmid-Ferguson dan Mohr. Data iklim yang diambil yaitu selama 10 tahun terakhir (20092018) yang diperoleh dari Badan Meteorologi dan Geofisika Stasiun meteorologi Manokwari Selatan berupa 
data curah hujan, hari hujan, temperatur, lama penyinaran selanjutnya dianalisis berdasarkan grafik. Setelah memperoleh karakteristik DAS dan iklim digunakan untuk memperoleh ketersediaan air. Data sekunder lainnya berupa kebutuhan air domestik dan non domestik yang ada di daerah penelitian dianalisis berdasarkan SNI 19-6728:1-2002 tentang kebutuhan air. Setelah diperoleh ketersediaan DAS yang mantap dan kebutuhan air maka didapatkan neraca DAS Muari.

\section{HASIL PENELITIAN}

Ada beberapa parameter yang digunakan dalam penelitian ini yaitu Iklim umum berupa data curah hujan dan hari hujan, temperatur, lama penyinaran dan indeks panas bulanan. Evapotranspirasi berupa evapotranspirasi belum terkoreksi dan terkoreksi. DAS berupa luas DAS, bentuk DAS, kapasitas tampung DAS, limpasan permukaan (Qp), ketersediaan air, kebutuhan air domestik dan non domestik serta neraca air.

a) Curah hujan dan hari hujan

Rata-rata curah hujan tahunan (Januari-Desember) yang jatuh di DAS Muari selama 10 tahun terakhir (2009-2018) mencapai 1762,3 mm. Curah hujan yang jatuh di permukaan tanah ada yang meresap ke dalam tanah dan ada yang tertinggal di permukaan tanah yang terbentuk menjadi air sungai. Berdasarkan data curah hujan bulanan selama 10 tahun terakhir (20092018), diketahui curah hujan tertinggi 186,1 mm pada bulan Maret dan curah hujan terendah 113,5 mm pada bulan Mei. Data curah hujan dapat dilihat pada Gambar 2.

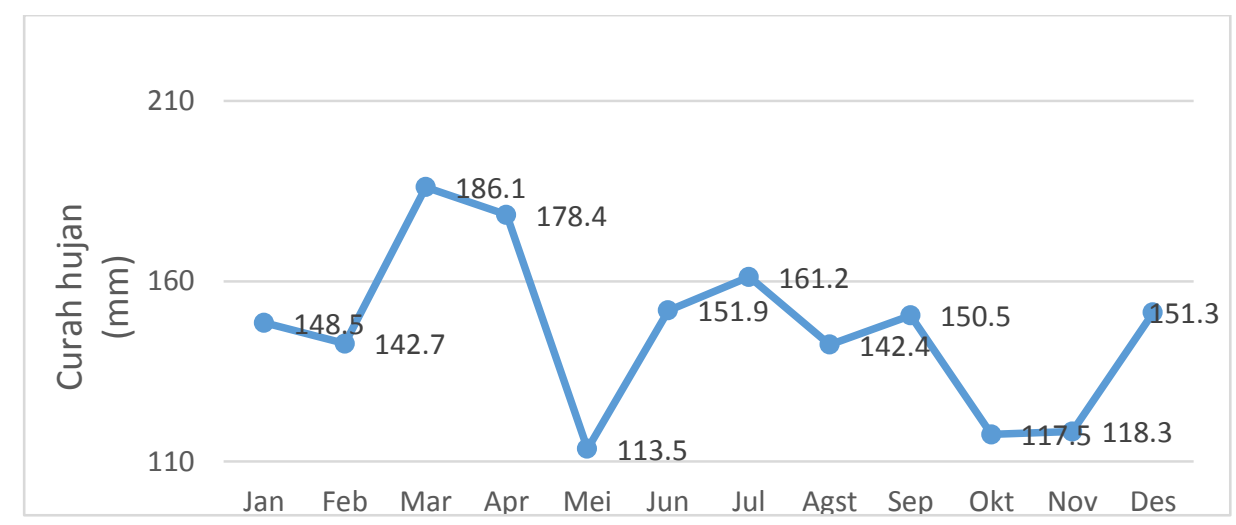

Gambar 2. Grafik curah hujan bulanan tahun 2009-2018

Curah hujan bulanan di daerah penelitian selama 10 tahun terakhir dari tahun (2009-2018) dianalisis berdasarkan klasifikasi iklim menurut Schmid-Ferguson dan Mohr. Berdasarkan klasifikasi SchmidFerguson diperoleh nilai $\mathrm{Q}=32 \%$ dari nilai curah hujan bulanan rata-rata selama 10 tahun terakhir (2009-2018). Nilai Q ini termasuk dalam tipe B yang dikategorikan sebagai daerah basah. Berdasarkan klasifikasi iklim menurut Mohr, dari nilai rata-rata banyaknya bulan kering dan rata-rata banyaknya bulan basah, diketahui daerah penelitian ini termasuk zona II dimana jumlah bulan kering berkisar antara 1-2 dan 
jumlah bulan basah berkisar antara 4-11.

Data tersebut dapat dilihat pada Tabel 1.

Tabel 1. Klasifikasi iklim menurut Schmid-Ferguson dan Mohr

\begin{tabular}{|c|c|c|c|c|c|c|c|c|c|c|}
\hline \multicolumn{11}{|c|}{ Klasifikasi iklim menurut Schmid-Ferguson } \\
\hline & 2009 & 2010 & 2011 & 2012 & 2013 & 2014 & 2015 & 2016 & 2017 & 2018 \\
\hline BK & 2 & 2 & 1 & 0 & 0 & 0 & 7 & 1 & 0 & 1 \\
\hline $\mathrm{BL}$ & 3 & 1 & 3 & 3 & 2 & 2 & 2 & 4 & 2 & 2 \\
\hline $\mathrm{BB}$ & 7 & 9 & 8 & 9 & 10 & 10 & 3 & 7 & 9 & 9 \\
\hline $\mathrm{Q}$ & 29 & 22 & 13 & 0 & 0 & 0 & 233 & 14 & 0 & 11 \\
\hline \multicolumn{9}{|c|}{ Rata-rata nilai $\mathrm{Q}$} & \multicolumn{2}{|c|}{$32 \%$} \\
\hline \multicolumn{11}{|c|}{ Klasifikasi iklim menurut Mohr } \\
\hline & 2009 & 2010 & 2011 & 2012 & 2013 & 2014 & 2015 & 2016 & 2017 & 2018 \\
\hline BK & 2 & 2 & 1 & 0 & 0 & 0 & 7 & 1 & 0 & 1 \\
\hline $\mathrm{BL}$ & 3 & 1 & 3 & 3 & 2 & 2 & 2 & 4 & 2 & 2 \\
\hline BB & 7 & 9 & 8 & 9 & 10 & 10 & 3 & 7 & 9 & 9 \\
\hline Zona & II & II & II & $\mathrm{Ib}$ & $\mathrm{Ib}$ & $\mathrm{Ib}$ & $\mathrm{V}$ & II & $\mathrm{Ib}$ & II \\
\hline \multicolumn{9}{|c|}{ Rata-rata zona } & \multicolumn{2}{|c|}{ II } \\
\hline
\end{tabular}

bulanan adalah 18 hari, dengan hari hujan November yaitu 14 hari. Data hari hujan terbanyak pada bulan Januari yaitu 19 hari dapat dilihat pada Gambar 3.

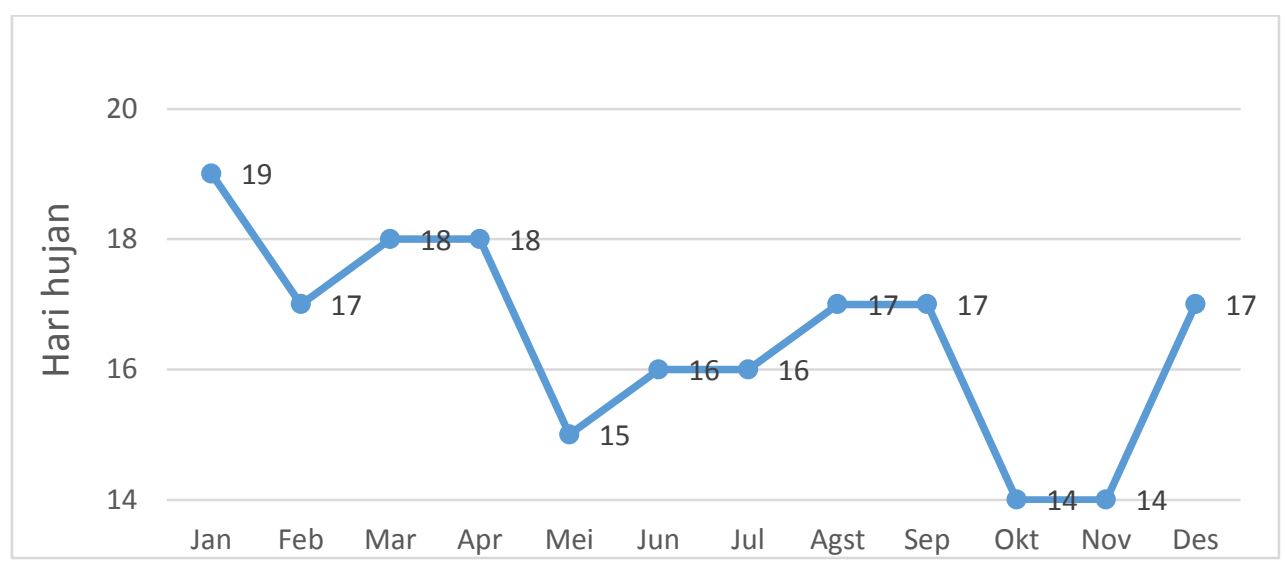

Gambar 3. Grafik rata-rata hari hujan tahun 2009-2018

b) Temperatur

Hasil yang diperoleh dari temperatur udara rata-rata maksimum bulanan adalah $27,3^{\circ} \mathrm{C}$ pada bulan Oktober, sedangkan untuk temperatur udara rata-rata minimum bulanan adalah $24,2^{\circ} \mathrm{C}$ pada bulan Juli. Data temperatur dapat dilihat pada Gambar 4.

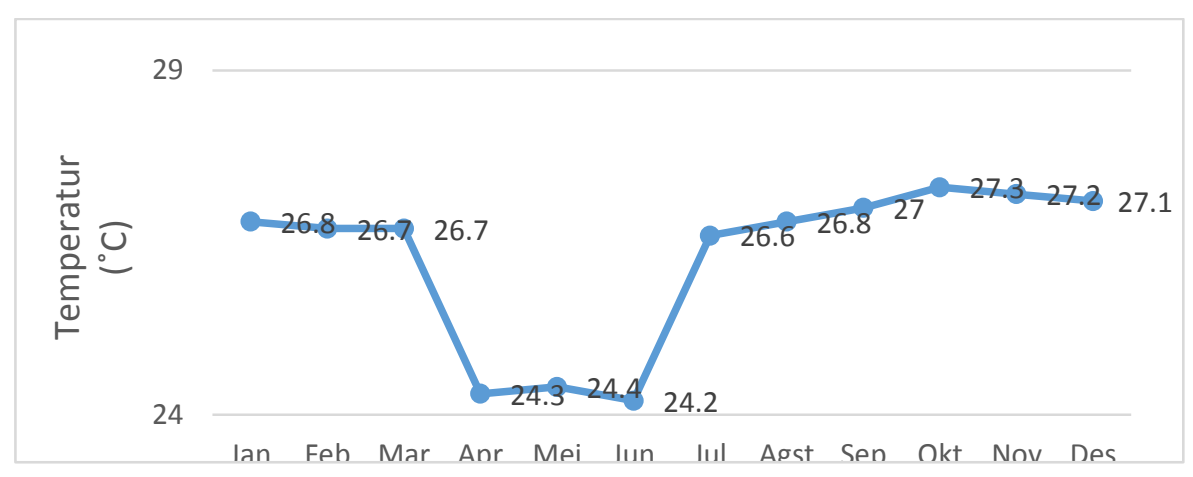

Gambar 4. Grafik temperatur rata-rata bulanan tahun 2009-2018 
c) Lama Penyinaran

Lama penyinaran rata-rata maksimum bulanan adalah 49,07\% pada bulan Mei, sedangkan lama penyinaran rata-rata minimum bulanan adalah $35,22 \%$ pada bulan Desember. Data lama penyinaran dapat dilihat pada Gambar 5.

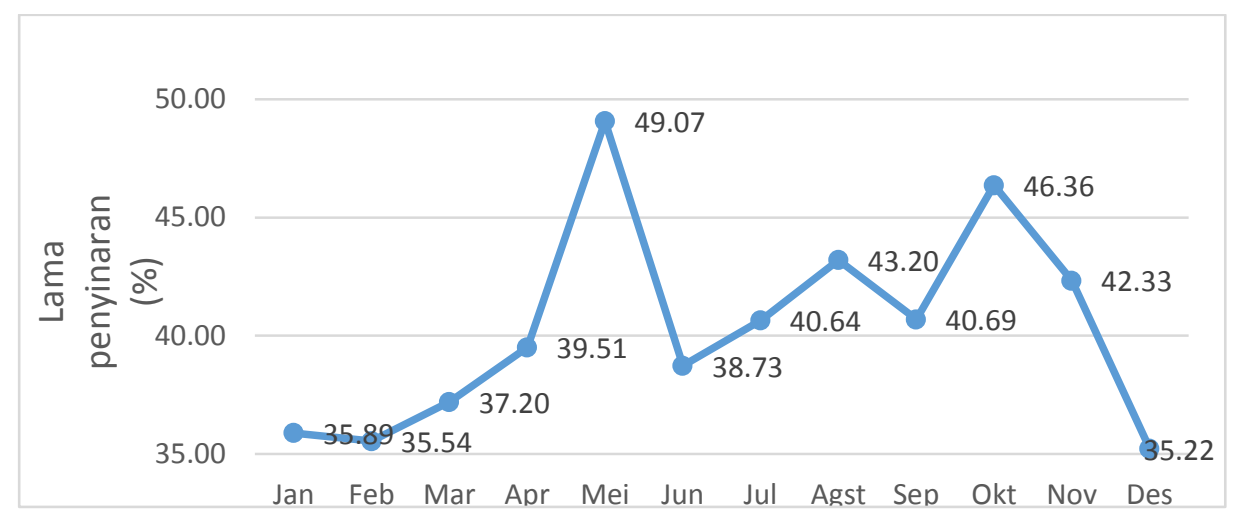

Gambar 5. Grafik lama penyinaran tahun 2009-2018

d) Indeks panas bulanan

Indeks panas bulanan pada daerah penelitian memiliki nilai maksimum 13,07\% pada bulan Oktober dan nilai minimum 10,89\% pada bulan Juni. Data indeks panas bulanan dapat dilihat pada Gambar 6 .

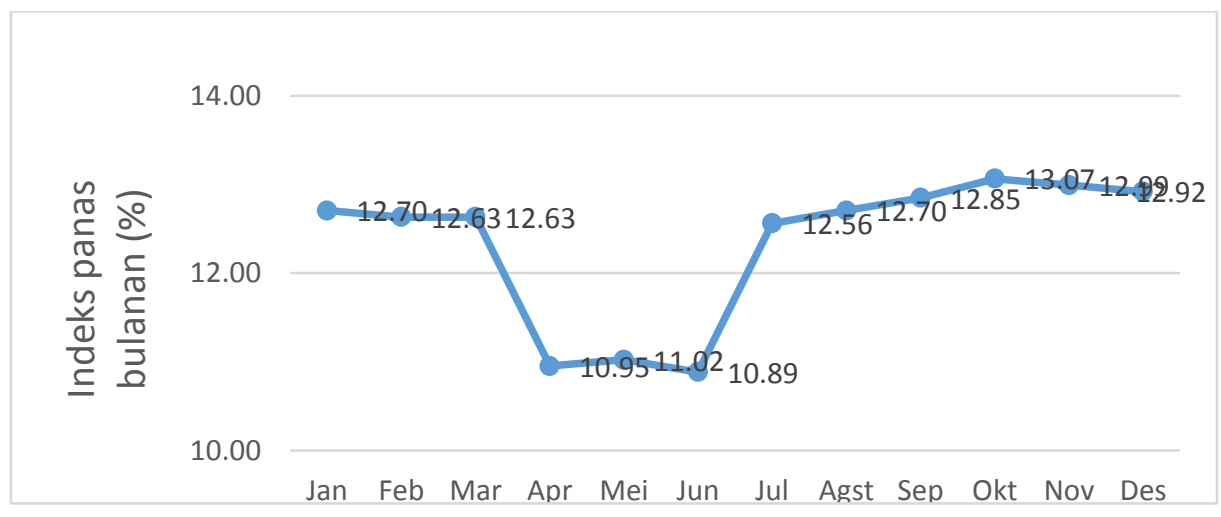

Gambar 6. Grafik indeks panas bulanan

e) Evapotranspirasi

Evapotranspirasi

keseluruhan jumlah total air yang

fisiologis vegetasi (Sumiharni dkk, 2016). Nilai evapotranspirasi di DAS Muari sebesar $100.835 .951,60 \mathrm{~m}^{3} /$ tahun. dikembalikan ke atmosfer serta berasal dari permukaan tanah, badan air dan vegetasi, serta adanya pengaruh iklim dan

- Evapotranspirasi Belum Terkoreksi (EPx) 


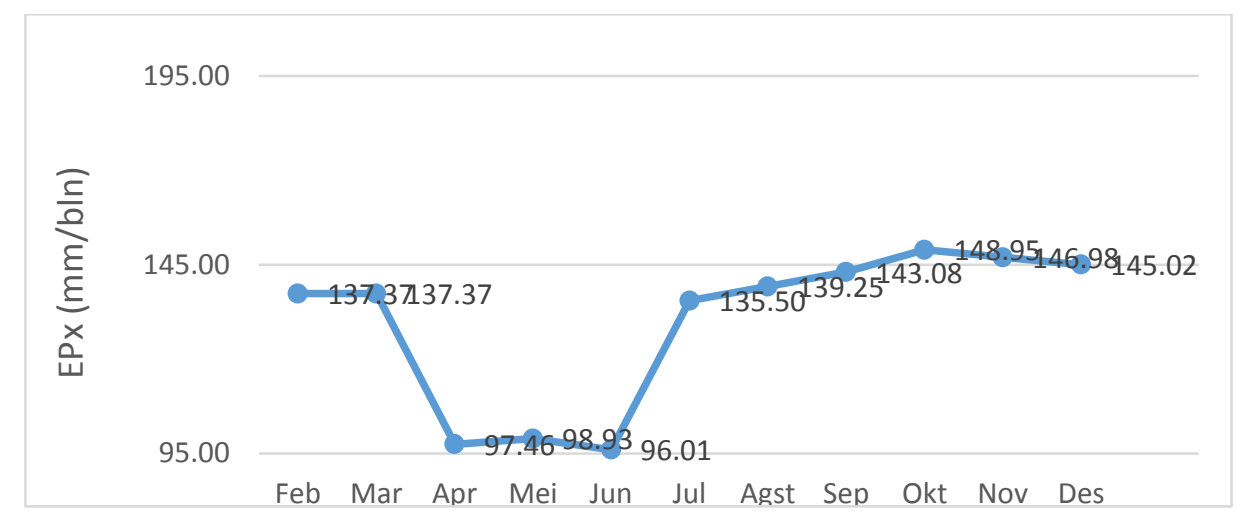

Gambar 7. Grafik nilai EPx

Nilai maksimum EPx 148,95 mm/bln terdapat pada bulan Oktober dan nilai minimum Epx 96,01 mm/bln pada bulan Juni. Rata-rata nilai EPx dari bulan JanuariDesember selama 10 tahun terakhir (20092018) yaitu $131,85 \mathrm{~mm} / \mathrm{bln}$. Data nilai evapotranspirasi potensial belum terkoreksi (EPx) dapat dilihat pada Gambar 7.
Nilai PET maksimum yaitu pada bulan Oktober sebesar $142,71 \mathrm{~mm} / \mathrm{bln}$ dan nilai PET minimum terjadi pada bulan Juni sebesar $74,37 \mathrm{~mm} / \mathrm{bln}$. Rata-rata nilai PET dari bulan Januari-Desember selama 10 tahun terakhir (2009-2018) yaitu $106,38 \mathrm{~mm} / \mathrm{bln}$. Data evapotranspirasi potensial terkoreksi (PET) dapat dilihat pada Gambar 8.

- Potensial Terkoreksi (PET)

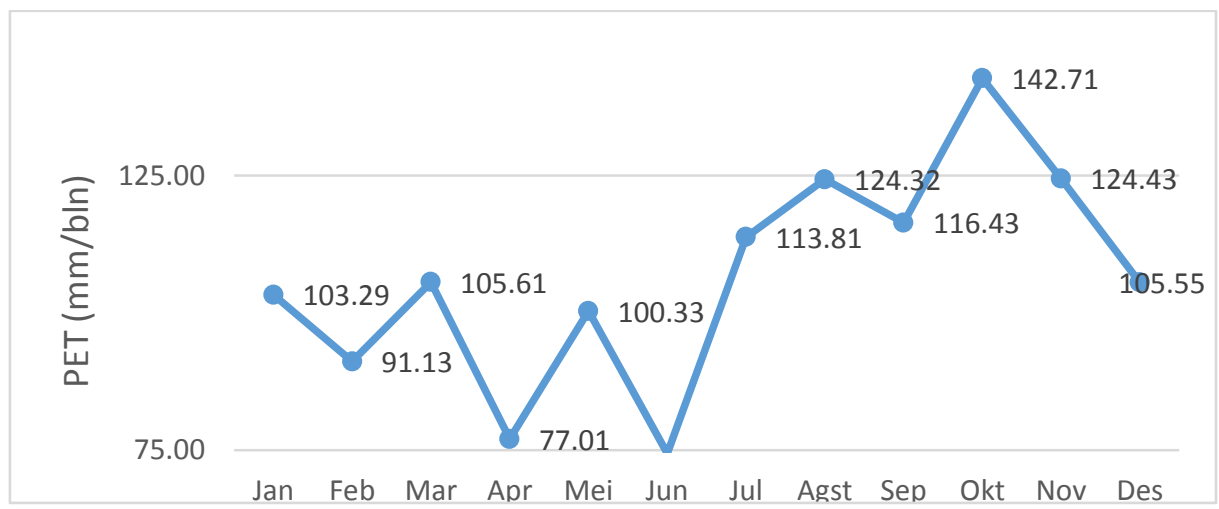

Gambar 8. Grafik nilai PET (Potensial Evapotrasnpirasi Terkoreksi)

\section{f) Luas DAS}

Luas daerah aliran sungai merupakan suatu luas daerah yang dapat di ukur dengan menggunakan peta topografi. Hasil pengolahan data menggunakan Arcgis sehingga didapatkan luas daerah DAS g) Bentuk DAS

Berdasarkan hasil perhitungan nilai RC di DAS Muari dengan luas DAS 78,8 sebesar 7884 ha atau 78,8 $\mathrm{km}^{2}$. Berdasarkan Peraturan Direktorat Jenderal Bina Pengelolaan DAS dan Perhutanan Sosial tahun 2013 (Ningkeula, 2016) luas DAS Muari termasuk dalam klasifikasi DAS sangat kecil dimana luas DAS $<10.000$ ha. $\mathrm{km}^{2}$ dan keliling $44,7 \mathrm{~km}^{2}$ didapatkan nilai $\mathrm{RC}=0,49$ sehingga bentuk DAS Muari ini merupakan bentuk memanjang. 
h) Kapasitas tampung DAS

Kapasitas tampung dari DAS Muari diperoleh dengan mengukur penampang kering (A) yang dibagi ke dalam segmensegmen. Nilai kapasitas tampung dihitung

Tabel 2. Kapasitas tampung DAS Muari menggunakan metode mean section kemudian dikalikan dengan kecepatan aliran (v) yang diperoleh dengan menggunakan rumus manning. Data kapasitas tampung DAS Muari dapat dilihat pada Tabel 2.

\begin{tabular}{|l|c|c|c|c|c|c|c|c|c|}
\hline No & Titik & $\left.\mathbf{A ~} \mathbf{( m}^{\mathbf{2}}\right)$ & $\mathbf{P}(\mathbf{m})$ & $\mathbf{S}$ & $\mathbf{R}$ & $\mathbf{N}$ & $\begin{array}{c}\mathbf{V} \\
(\mathbf{m} / \mathbf{s})\end{array}$ & $\begin{array}{c}\mathbf{( Q )} \\
(\mathbf{m} / \mathbf{s})\end{array}$ & $\begin{array}{c}\text { Kapasitas (Qt) } \\
\left(\mathbf{m}^{\mathbf{3}} / \mathbf{h a r i}\right)\end{array}$ \\
\hline 1. & Titik 1 & 104,8 & 275 & 0,006 & 0,4 & 0,045 & 0,9 & 95 & 8.188 .731 \\
\hline 2. & Titik 2 & 109,5 & 115 & 0,03 & 1,0 & 0,045 & 3,7 & 408 & 35.219 .996 \\
\hline 3. & Titik 3 & 55,6 & 164 & 0,005 & 0,3 & 0,045 & 0,8 & 43 & 3.675 .084 \\
\hline
\end{tabular}

Dilihat dari Tabel 2 nilai $Q$ sesaat terbesar terdapat pada titik ke 2 yaitu $408 \mathrm{~m}^{3} / \mathrm{s}$, sedangkan $Q$ sesaat terendah yaitu pada titik ke 3 sebesar $43 \mathrm{~m}^{3} / \mathrm{s}$. Kapasitas tampung DAS Muari nilai terbesar terdapat pada titik ke 2 yaitu sebesar $35.219 .996 \mathrm{~m}^{3} / \mathrm{s}$, sedangkan yang terendah pada titik ke 3 sebesar $3.675 .084 \mathrm{~m}^{3} / \mathrm{s}$.

i) Run off

Limpasan permukaan adalah air hujan yang tidak bisa tertahan oleh tanah,

Tabel 3. Data Run Off Daerah Penelitian tumbuhan, atau cekungan dan akhirnya akan mengalir langsung ke sungai maupun laut. Limpasan permukaan (run off) dari daerah penelitian dapat dihitung berdasarkan koefisien limpasan permukaan pada tutupan lahan dan nilai intensitas maksimum (I). Pada peta tutupan lahan terdapat 4 daerah yaitu daerah hutan, semak belukar, pertanian dan pemukiman. Nilai run off (Qp) dihitung untuk masing-masing bulan (JanuariDesember) yang dapat dilihat pada Tabel 3.

\begin{tabular}{|c|c|c|c|c|c|c|}
\hline No & Bulan & $\begin{array}{c}\text { Tutupan } \\
\text { Lahan }\end{array}$ & $\begin{array}{c}\text { Qp } \\
\left(\mathbf{m}^{3} / \text { hari }\right)\end{array}$ & Bulan & Tutupan Lahan & $\begin{array}{c}\text { Qp } \\
\left(\mathbf{m}^{3} / \mathbf{h} \text { ari) }\right.\end{array}$ \\
\hline \multirow{5}{*}{1} & \multirow{5}{*}{ Jan } & Hutan & 159.908 & \multirow{5}{*}{ Jul } & Hutan & 199.885 \\
\hline & & Semak Belukar & 54.872 & & Semak Belukar & 68.590 \\
\hline & & Pertanian & 16.443 & & Pertanian & 20.553 \\
\hline & & Pemukiman & 8.365 & & Pemukiman & 10.456 \\
\hline & & Total Qp & 239.588 & & Total Qp & 299.485 \\
\hline \multirow{5}{*}{2} & \multirow{5}{*}{ Feb } & Hutan & 159.908 & \multirow{5}{*}{ Agst } & Hutan & 159.908 \\
\hline & & Semak Belukar & 54.872 & & Semak Belukar & 54.872 \\
\hline & & Pertanian & 16.443 & & Pertanian & 16.443 \\
\hline & & Pemukiman & 8.365 & & Pemukiman & 8.365 \\
\hline & & Total Qp & 239.588 & & Total Qp & 239.588 \\
\hline \multirow{5}{*}{3} & \multirow{5}{*}{ Mar } & Hutan & 199.885 & \multirow{5}{*}{ Sep } & Hutan & 179.896 \\
\hline & & Semak Belukar & 68.590 & & Semak Belukar & 61.731 \\
\hline & & Pertanian & 20.553 & & Pertanian & 18.498 \\
\hline & & Pemukiman & 10.456 & & Pemukiman & 9.411 \\
\hline & & Total Qp & 299.485 & & Total Qp & 269.536 \\
\hline \multirow{3}{*}{4} & \multirow{3}{*}{ Apr } & Hutan & 199.885 & \multirow{3}{*}{ Okt } & Hutan & 159.908 \\
\hline & & Semak Belukar & 68.590 & & Semak Belukar & 54.872 \\
\hline & & Pertanian & 20.553 & & Pertanian & 16.443 \\
\hline
\end{tabular}




\begin{tabular}{|c|c|c|c|c|c|c|}
\hline & & Pemukiman & 10.456 & & Pemukiman & 8.365 \\
\hline & & Total Qp & 299.485 & & Total Qp & 239.588 \\
\hline \multirow{5}{*}{5} & \multirow{5}{*}{ Mei } & Hutan & 159.908 & \multirow{5}{*}{ Nov } & Hutan & 179.896 \\
\hline & & Semak Belukar & 54.872 & & Semak Belukar & 61.731 \\
\hline & & Pertanian & 16.443 & & Pertanian & 18.498 \\
\hline & & Pemukiman & 8.365 & & Pemukiman & 9.411 \\
\hline & & Total Qp & 239.588 & & Total Qp & 269.536 \\
\hline \multirow[t]{6}{*}{6} & Jun & Hutan & 179.896 & Des & Hutan & 179.896 \\
\hline & & Semak Belukar & 61.731 & & Semak Belukar & 61.731 \\
\hline & & Pertanian & 18.498 & & Pertanian & 18.498 \\
\hline & & Pemukiman & 9.411 & & Pemukiman & 9.411 \\
\hline & & Total Qp & 269.536 & & Total Qp & 269.536 \\
\hline & & \multicolumn{3}{|c|}{ Total Qp } & \multicolumn{2}{|c|}{ 3.174.535,95 } \\
\hline
\end{tabular}

j) Ketersediaan air

Ketersediaan air merupakan air yang

berasal dari hujan, air permukaan dan air

Tabel 4. Ketersediaan air tanah. Data ketersediaan air dapat dilihat pada Tabel 4.

Luas DAS $\left(\mathrm{km}^{2}\right)$
P-Ea $(\mathrm{mm})$
Total Ketersediaan Air (Ro)
Ketersediaan air DAS mantap (Pa)

k) Kebutuhan air

Data kebutuhan air domestik dan non domestik di Distrik Orans Bari dapat dilihat pada Tabel 5 dan tabel 6. Dari Tabel 6 dapat dilihat bahwa kebutuhan air non domestik terbesar yaitu pada kebutuhan air pertanian sedangkan yang terendah yaitu pada

\section{8,8}

228,34

$18.002 .325 \mathrm{~m}^{3} /$ tahun

$5.400 .697,68 \mathrm{~m}^{3} /$ tahun

Tabel 5. Kebutuhan air domestik

\begin{tabular}{|l|l|l|l|}
\hline No & Kampung & $\begin{array}{l}\text { Jumlah } \\
\text { (Jiwa) }\end{array}$ & $\begin{array}{l}\text { Konsumsi air } \\
\left(\mathbf{m}^{\mathbf{3}} / \text { Tahun) }\right.\end{array}$ \\
\hline 1. & Warbiadi & 360 & 7.884 \\
\hline 2. & Waroser & 502 & $10.993,8$ \\
\hline 3. & Sindang Jaya & 704 & $15.417,6$ \\
\hline 4. & Sidomulyo & 977 & $21.396,3$ \\
\hline 5. & Akeju & 229 & $5.015,1$ \\
\hline 6. & Margorukun & 365 & $7.993,5$ \\
\hline 7. & Margomulyo & 457 & $10.008,3$ \\
\hline 8. & Muari & 647 & $14.169,3$ \\
\hline \multicolumn{2}{|l|}{ Total } & $\mathbf{4 2 4 1}$ & $\mathbf{9 2 . 8 7 7 , 9}$ \\
\hline \multicolumn{2}{|l}{ Total konsumsi air $\left(\mathbf{m}^{\mathbf{3}} /\right.$ tahun) } & $\mathbf{9 2 . 8 7 7 , 9}$ \\
\hline
\end{tabular}


Tabel 6. Kebutuhan air non domestik

\begin{tabular}{llc}
\hline No & \multicolumn{1}{c}{ Kebutuhan air } & $\begin{array}{c}\text { Total kebutuhan air } \\
\left(\mathbf{m}^{\mathbf{3}} / \mathbf{t a h u n}\right)\end{array}$ \\
\hline 1. & Kebutuhan air peternakan & $47.833,15$ \\
2. & Kebutuhan air pertanian & 4.430 .000 \\
3. & Kebutuhan air untuk sekolah & $7.208,75$ \\
4. & Kebutuhan air untuk penginapan & 952,65 \\
\hline
\end{tabular}

1) Neraca air

ditentukan jumlah air kelebihan (surplus)

Neraca air merupakan jumlah ataupun defisit (kekurangan). Neraca air masukkan dan keluaran air di suatu tempat DAS Muari dapat dilihat pada Tabel 7. pada periode tertentu, sehingga dapat

Tabel 7. Neraca air DAS Muari

\begin{tabular}{ll}
\hline Ketersediaan Air dan Kebutuhan Air & Jumlah $\mathbf{~ m}^{\mathbf{3}} /$ tahun \\
\hline Ketersediaan Air DAS & 18.002 .325 \\
Ketersediaan Air DAS Mantap & $5.400 .697,68$ \\
Kebutuhan Domestik & $92.877,9$ \\
Kebutuhan Non Domestik & $4.485 .994,55$ \\
\hline
\end{tabular}

Dari Tabel 7 diatas dapat dihitung neraca air DAS Muari dimana Ketersediaan air DAS mantap dikurangi dengan total kebutuhan air domestik dan non domestik sehingga neraca air DAS Muari sebesar $821.825,23 \mathrm{~m}^{3} /$ tahun. Berdasarkan klasifikasi cadangan dan pemanfaatan air per daerah pengairan sungai berdasarkan SNI 19-6728.1-2002, neraca DAS Muari termasuk dalam klasifikasi I dimana potensi airnya berkisar antara 015000 juta $\mathrm{m}^{3}$ dan pemanfaatan air 0-900 juta $\mathrm{m}^{3}$.

\section{KESIMPULAN}

Kesimpulan dari penelitian ini yaitu:

1. Daerah aliran sungai (DAS) Muari memiliki total ketersediaan air (Ro) sebesar $\quad 18.002 .325 \quad \mathrm{~m}^{3} /$ tahun, sedangkan ketersediaan air DAS yang mantap (Pa) sebesar 5.400.697,68 $\mathrm{m}^{3} /$ tahun
2. Kebutuhan air domestik daerah aliran sungai (DAS) Muari sebesar 92.877,9 $\mathrm{m}^{3} /$ tahun, sedangkan kebutuhan non domestik sebesar 4.485.994,55 $\mathrm{m}^{3} /$ tahun.

3. Neraca daerah aliran sungai (DAS) Muari sebesar 821.825,23 $\mathrm{m}^{3} /$ tahun atau $(15 \%)$ dari ketersediaan air DAS yang mantap, nilai ini menunjukkan bahwa DAS Muari mengalami surplus.

\section{DAFTAR PUSTAKA}

Admadhani, D.N., Haji, A.T.S., Susanawati, L.D. 2014. Analisis Ketersediaan Air Untuk Daya Dukung Lingkungan (Studi Kasus Kota Malang). Jurnal Sumberdaya Alam dan Lingkungan.

Badan Standardisasi Nasional. 2002. Penyusunan neraca sumber daya Bagian 1: Sumber daya air spasial. 
Standar Nasional Indonesia, SNI 19-6728.1-

Bayuaji, I.S. 2015. Analisis Imbangan

Ketersediaan dan Kebutuhan Air Pertanian dan Domestik di DAS Pemali. Artikel Ilmiah. Universitas Padjajaran Bandung.

Mentang, R.S., Mananoma, T., Sumarauw, J.S.F. 2017. Analisis Neraca Air Sungai Paniki Dengan Titik Tinjauan di Jembatan Paniki. Jurnal Sipil Statik. Vol 5, No 3.
2002.

Sumiharni., Siregar, A.M., Ananta, K.H. 2016. Studi Kasus Penggunaan Sumber Daya Air di Daerah Aliran Sungai (DAS) Way Ketibung Kabupaten Lampung Selatan. Jurnal Rekayasa. Vol 20, No 2. Undang-Undang Rebuplik Indonesia No 7 Tahun 2004 Tentang Sumberdaya Air 